\title{
Assessment of functional capacity among students with univentricular heart
}

\author{
Camila Ampuero, M.D. ${ }^{a}$, Richard Silva, B.S. ${ }^{b}$, Paulo Valderrama, M.D. ${ }^{c}$, Emilio Covarrubias, B.S. ${ }^{b}$, \\ Patricio Astudillo, M.D. ${ }^{a}$, Pamela Zelada, M.D. ${ }^{c, d}$ and Cristian Clavería, M.D. ${ }^{c}$
}

\begin{abstract}
A cross-sectional study was done in students with univentricular heart after undergoing total cavopulmonary connection (Fontan procedure) to establish their baseline functional capacity based on the six-minute walk test and identify potential determining factors. Thirty patients were included; their median age was 12 years old. Eighteen patients were males. The median distance walked was 551.3 meters, 84 $\%$ of the theoretical distance for a healthy pediatric population. Height, pre-test systolic blood pressure, and resting arterial oxygen saturation showed a significant association with the distance walked in the multiple linear regression model. No significant association was observed in the meters walked in terms of the following outcome measures: sex, nutritional status, baseline cardiological diagnosis, number of prior surgeries, and age at the time of Fontan procedure.

Key words: six-minute walk test, cardiac rehabilitation, Fontan procedure, child, exercise tolerance.
\end{abstract}

http: / / dx.doi.org/ 10.5546/ aap.2020.eng.343

To cite: Ampuero C, Silva R, Valderrama P P, Covarrubias E, et al. Assessment of functional capacity among students with univentricular heart. Arch Argent Pediatr 2020;118(5):343-347.

a. Department of Pediatrics, School of Medicine, Pontificia Universidad Católica de Chile.

b. Department of Kinesiology, Hospital Clínico Red de Salud UC-CHRISTUS.

c. Department of Pediatric Cardiology and Respiratory Diseases, Department of Pediatrics, School of Medicine, Pontificia Universidad Católica de Chile.

d. Unit of Pediatric Cardiology. Department of Pediatrics. Complejo Asistencial Dr. Sótero del Río, Santiago, Chile.

E-mail address: Cristian Clavería, M.D.: claveria@med.puc.cl

Funding: None.

Conflict of interest: None.

Received: 10-24-2019

Accepted: 5-14-2020

\section{INTRODUCTION}

Fontan procedure is a palliative surgical procedure performed in patients with univentricular (UV) heart that has allowed for an increased survival in this population. The advantages of this new procedure include the normalization of arterial blood oxygen saturation $\left(\mathrm{SaO}_{2}\right)$ and the elimination of chronic volume overload at the expense of increasing systemic venous pressure and reducing cardiac output at rest and during exercise. ${ }^{1}$

Functional capacity (FC) is an independent predictor of morbidity and mortality in patients with congenital heart disease (CHD), including those with UV heart. Their assessment is important to collect information about cardiopulmonary system health and the factors that may compromise it. ${ }^{2}$

The six-minute walk test (6MWT) is a safe, simple, and low-cost method to measure FC in healthy children with standard values that allow to make comparative studies. ${ }^{3}$ Its use in children with $\mathrm{CHD}$ has been useful and reliable in the assessment and follow-up in rehabilitation programs. ${ }^{4}$

This study sought to determine FC using the $6 \mathrm{MWT}$ in patients with UV heart who are currently in the period after Fontan procedure and identify potential determining factors.

\section{POPULATION AND METHOD Patients}

This was a cross-sectional study in patients aged 6-16 years diagnosed with UV heart after undergoing Fontan procedure at Hospital Clínico UC-CHRISTUS between 2000 and 2013. Participants were selected by convenience sampling based on the review of the hospital's database. Patients who received oxygen, used beta-blockers, had a pacemaker or were diagnosed with arrhythmia were excluded. Subjects with orthopedic or neurological conditions that restricted test performance were also excluded. Patients under cardiological follow-up living in the Metropolitan Region of Chile were contacted by telephone. Demographic data and medical history of each patient were 
documented by means of a survey administered to parents and/or legal guardians or a review of electronic medical records.

Baseline cardiological diagnosis was classified into three groups based on ventricular morphology: right UV, left UV, and biventricular and/or indeterminate morphology. Age at the time of Fontan procedure was described in months, and patients were divided into those undergoing early surgery (at 36 months old or younger) versus those undergoing late surgery (older than 36 months). ${ }^{5}$ Based on the number of surgeries, patients were classified into two groups: a) 3 or less; b) more than 3 cardiac surgeries with cardiopulmonary bypass (CBP), and both groups were compared in terms of the meters walked during the test.

In general, two or three stages are required to complete the Fontan procedure. ${ }^{1}$ A higher number of surgeries with ECC implies the presence of residual defects and/or complications with a negative effect on cardiopulmonary function. ${ }^{6}$

The 6MWT was administered by two kinesiologists in accordance with the American Thoracic Society guidelines, ${ }^{7}$ in a closed setting, on a 30-meter long flat surface with one cone placed at each end of the course. The total distance walked in meters was measured and compared to the reference values for the healthy pediatric population. ${ }^{3}$ The following outcome measures were recorded at the beginning and end of the 6MWT: heart rate (HR) and $\mathrm{SaO}_{2}$ as measured with a pulse oximeter (Nonin Onyx Vantage 9590, Minnesota, USA), blood pressure (BP) as measured with a digital sphygmomanometer (GE Critikon Dinamap XL Vital Signs Monitor, USA), and subjective perception of fatigue and dyspnea as per the Modified Borg Scale. ${ }^{8}$ The nutritional assessment was based on the body mass index for age (BMI/A) rate according to the World Health Organization (WHO) standards. ${ }^{9}$

\section{Statistical analysis}

The SPSS V25.0 software (NY, USA) was used for statistical analysis. Numerical outcome measures were described as median and interquartile range (IQR). Independent samples were analyzed using the Mann-Whitney U test and dependent samples, with the Wilcoxon signed-rank test. The Kruskal-Wallis test and Dunn's post-test were done to assess the distance walked in the 6MWT with the baseline cardiological diagnosis or number of surgeries.

A multiple linear regression adjusted for age, weight, height, BMI, systolic BP, diastolic BP, mean $\mathrm{BP}, \mathrm{HR}$, and $\mathrm{SaO}_{2}$ was done for the distance walked in the 6MWT. A value of $p<0.05$ was considered significant.

\section{Ethics}

The study was approved by the Research Ethics Committee of the School of Medicine of Pontificia Universidad Católica de Chile (ID code: 161205006). Parents and/or legal guardians signed an informed consent, and patients older than 7 years gave their informed assent.

\section{RESULTS}

\section{Clinical and demographic characteristics}

A total of 105 patients with UVH underwent Fontan procedure between 2000 and 2013; of them, 30 patients were enrolled for the 6MWT as described in the flow chart shown in Figure 1. All patients included in the study underwent Fontan procedure with an extracardiac conduit; of these, 26 underwent a fenestrated procedure. The demographic and clinical characteristics of enrolled patients are summarized in Table 1.

FIGURE 1. Flow chart of patients with univentricular heart after total right ventricular bypass who underwent Fontan procedure between 2000 and 2013 at Hospital Clínico Red Salud UC-CHRISTUS

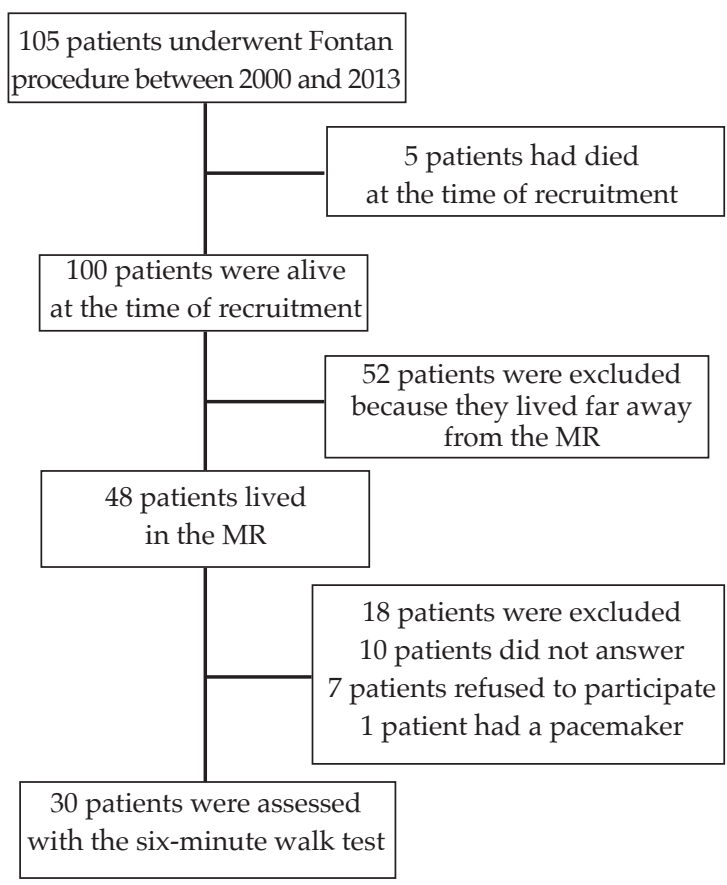

MR: Metropolitan Region of Chile. 


\section{Six-minute walk test results}

All patients completed the 6MWT without interruptions. No complications were observed during or after the test. Pre- and post-test physiological parameters are shown in Table 2. When the Borg Modified Scale was administered after completing the test, 27 patients reported some extent of dyspnea and 21, some extent of muscle fatigue. The median distance walked at the end of the test was 551.3 meters, which corresponded to $84 \%$ of the average theoretical distance for the healthy pediatric population, which accounted for a statistically significant difference $(p<0.001)$. The analysis of factors that may have affected the distance walked showed that there was no association with sex $(p=0.85)$, nutritional status $(p=0.52)$, early age at the time of Fontan procedure $(p=0.1)$, baseline cardiological diagnosis $(p=0.57)$ or more than 3 cardiac surgeries with CPB $(p=0.37)$. A multiple linear regression model was done to predict the distance walked in the 6MWT with the demographic and physiological outcome measures prior to the test. Height, pre-test systolic $\mathrm{BP}$, and resting $\mathrm{SaO}_{2}$ were significant $\left(p<0.05 ; \mathrm{R}^{2}\right.$ : 0.58) (Table 3).

\section{DISCUSSION}

Patients with UVH assessed with the 6MWT walked a shorter distance than healthy subjects of the same age as studied by Geiger et al. ${ }^{3}$ Such difference in the meters walked has been associated with the underlying disease or differences in height between both populations. ${ }^{4,10,11}$ In relation to potential determining factors for the distance walked, no significant relation was observed in terms of sex, ventricular morphology, number of prior surgeries, nutritional status, and age at the time of Fontan procedure. In other series, these factors have shown to affect aerobic capacity. ${ }^{4-6,12,13}$ This may be because of our small, heterogeneous sample size. In relation to pre- and post-test physiological parameters, a physiological pressor and chronotropic response to exercise was observed, consistent with what has been previously described. ${ }^{14}$ It is worth mentioning that the post-test reduced $\mathrm{SaO}_{2}$ observed in certain patients may be explained by the presence of patent fenestration, veno-venous connections or arteriovenous fistulas. ${ }^{14,15}$ The multiple linear

TABLE 1. Demographic and clinical characteristics of recruited patients who had univentricular heart after Fontan procedure $(\mathrm{N}=30)$

\begin{tabular}{|c|c|}
\hline Characteristic & Patients, n $(\%)^{a}$ \\
\hline Male sex & $18(60)$ \\
\hline Age (years) & $12(8.75-14)$ \\
\hline Height (cm) & $145(129-156)$ \\
\hline \multicolumn{2}{|l|}{ Nutritional status } \\
\hline Malnourished & $2(6.7)$ \\
\hline Normal weight & $18(60)$ \\
\hline Overweight & $9(30)$ \\
\hline Obese & $1(3.3)$ \\
\hline \multicolumn{2}{|l|}{ Cardiological diagnosis } \\
\hline Right univentricular heart & $17(56.7)$ \\
\hline Left univentricular heart & $9(30)$ \\
\hline Biventricular & $4(13.3)$ \\
\hline \multicolumn{2}{|l|}{ No. of surgeries } \\
\hline$\leq 3$ cardiac surgeries with $\mathrm{CPB}$ & $21(70)$ \\
\hline$>3$ cardiac surgeries with $\mathrm{CPB}$ & $9(30)$ \\
\hline \multicolumn{2}{|c|}{ Age at the time of Fontan procedure (months) 36.5 (33-41) } \\
\hline Distance walked (m) & $551.3(502.3-603.8)$ \\
\hline
\end{tabular}

TABle 2. Physiological parameters, dyspnea, and fatigue based on the Borg Modified Scale before and after the six-minute walk test in patients with univentricular heart after Fontan procedure $(N=30)^{a}$

\begin{tabular}{|c|c|c|c|}
\hline Outcome measure & Pre-6MWT & Post-6MWT & $p$ value \\
\hline HR, bpm & $81(58-92)$ & $118.5(103-125)$ & $<0.001$ \\
\hline $\mathrm{SaO}_{2}, \%$ & $95(92-96)$ & $92(88-94)$ & $<0.001$ \\
\hline $\mathrm{SBP}, \mathrm{mmHg}$ & 109 (104-119) & 113.5 (108-127) & 0.002 \\
\hline $\mathrm{DBP}, \mathrm{mmHg}$ & $61(55-66)$ & $68(62-73)$ & $<0.001$ \\
\hline Dyspnea & $0(0-1)$ & $4(3-5)$ & $<0.001$ \\
\hline Fatigue & $0(0-0)$ & $0(0-4)$ & $<0.001$ \\
\hline
\end{tabular}

a Data were described as median and interquartile range.

$\mathrm{HR}$ : heart rate; bpm: beats per minute; $\mathrm{SaO}_{2}$ : arterial blood oxygen saturation; SBP: systolic blood pressure;

DBP: diastolic blood pressure; 6MWT: six-minute walk test. 
TABLE 3. Multiple linear regression model adjusted for the distance walked in the six-minute walk test by recruited patients who had univentricular heart after Fontan procedure $(N=30)$

\begin{tabular}{lcc}
\hline Outcome measure & $\beta$ & $p$ value \\
\hline Age (years) & 0.022 & 0.93 \\
Weight $(\mathrm{kg})$ & -0.191 & 0.51 \\
Height $(\mathrm{m})$ & 0.47 & $0.001^{*}$ \\
$\mathrm{BMI}\left(\mathrm{kg} / \mathrm{m}^{2}\right)$ & -0.93 & 0.53 \\
Pre-6MWT SBP & 0.29 & $0.043^{*}$ \\
Pre-6MWT DBP & -0.065 & 0.65 \\
Pre-6MWT MBP & 0.017 & 0.94 \\
Pre-6MWT HR & -0.065 & 0.64 \\
Pre-6MWT SaO & 0.384 & 0.006 \\
\hline
\end{tabular}

${ }^{*} \mathrm{R}: 0.76 ; \mathrm{R}^{2}: 0.58$.

* Significant.

BMI: body mass index; SBP: systolic blood pressure; DBP: diastolic blood pressure; MBP: mean blood pressure;

6MWT: six-minute walk test; $\mathrm{HR}$ : heart rate; $\mathrm{SaO}_{2}$ : arterial blood oxygen saturation.

regression model determined an equation where height, systolic $\mathrm{BP}$ and pre-test $\mathrm{SaO}_{2}$ predicted, by $58 \%$, the distance walked in our sample of patients.

Although the cardiopulmonary exercise testing (CPET) is the most objective test to measure $\mathrm{FC}^{14}$ the $6 \mathrm{MWT}$ offers two advantages over the CPET: it is simple and low cost and, being a submaximal exercise test, it may be performed by subjects who cannot tolerate maximal exercise. ${ }^{7}$ In addition, its similarity with daily life activities allow the 6MWT to determine FC in these patients, with an adequate correlation between the distance walked and oxygen consumption as measured by the CPET. ${ }^{4}$

Some of the limitations of this study are its small sample size and lack of stratification, in addition to a non-randomized sample selected by convenience. Future studies are required that consider age and sex stratification to achieve a greater representation of this patient population so as to obtain reference values for comparative studies and thus lay the foundation for the development of pediatric cardiac rehabilitation programs.

\section{REFERENCES}

1. Rychik J, Atz A, Celermajer D, Deal B, et al. Evaluation and management of the child and adult with Fontan circulation. AScientific Statement from the American Heart Association. Circulation. 2019; 140:e234-84.

2. Ohuchi H, Negishi J, Noritake K, Hayama Y, et al. Prognostic value of exercise variables in 335 patients after the Fontan operation: a 23-year single-center experience of cardiopulmonary exercise testing. Congenit Heart Dis. 2015; 10(2):105-16.
3. Geiger R, Strasak A, Treml B, Gasser K, et al. Six-minute walk test in children and adolescents. J Pediatr. 2007; 150(4):395-9.e1-2.

4. Moalla W, Gauthier R, Maingourd Y, Ahmaidi S. Sixminute walking test to assess exercise tolerance and cardiorespiratory responses during training program in children with congenital heart disease. Int J Sports Med. 2005; 26(9):756-62.

5. Daley M, d'Udekem Y. In patients undergoing Fontan completion, does a younger age at operation result in better long-term exercise capacity and prognosis? Interact Cardiovasc Thoracic Surg. 2019; 28(2):301-5.

6. Jacobs JP, Mavroudis C, Quintessenza JA, Chai PJ, et al. Reoperations for pediatric and congenital heart disease: an analysis of the Society of Thoracic Surgeons (STS) congenital heart surgery database. Semin Thorac Cardiovasc Surg Pediatr Card Surg Annu. 2014; 17(1):2-8.

7. ATS Committee on Proficiency Standards for Clinical Pulmonary Function Laboratories. ATS statement: guidelines for the six-minute walk test. Am J Respir Crit Care Med. 2002; 166(1):111-7.

8. Borg GA. Psychophysical bases of perceived exertion. Med Sci Sports Exerc. 1982; 14(5):377-81.

9. Word Health Organization. WHO reference 2007. Growth reference data for 5-19 years. [Accessed on: May 14 $\left.{ }^{\text {th }}, 2020\right]$. Available at: https: / / www.who.int/growthref/en/.

10. Feltez G, Coronel CC, Pellanda LC, Lukrafka JL. Exercise capacity in children and adolescents with corrected congenital heart disease. Pediatr Cardiol. 2015; 36(5):107582.

11. Schaan CW, Feltez G, Schaan BD, Pellanda LC. Functional capacity in children and adolescents with congenital heart disease. Rev Paul Pediatr. 2019; 37(1):65-72.

12. Kamata M, Stiver C, Naguib A, Tumin D, et al. A retrospective analysis of the influence of ventricular morphology on the perioperative outcomes after Fontan surgery. J Cardiothorac Vasc Anesth. 2017; 31(1):128-33.

13. Makni E, Elloumi A, Ben Brahim M, Moalla W, et al. Sixminute walk distance equation in children and adolescents with obesity. Acta Paediatr. 2020 [In press]. 
14. Rhodes J. Fontan circulation. In Rhodes J, Alexander M, Opotowsky A (eds.). Exercise Physiology for the Pediatric and Congenital Cardiologist. Switzerland: Springer; 2019. Pages 97-115.
15. Sen S, Bandyopadhyay B, Eriksson P, Chattopadhyay A. Functional capacity following univentricular repair-midterm outcome. Congenit Heart Dis. 2012; 7(5):423-32. 